\title{
Retraction Note to: A Planning Tool for TV White Space Deployments
}

\author{
Mahesh Iyer and Mythili Vutukuru
}

\section{Retraction Note to: \\ Chapter "A Planning Tool for TV White Space Deployments" in: P. Marques et al. (Eds.): Cognitive Radio Oriented \\ Wireless Networks, LNICST 228, https://doi.org/10.1007/978-3-319-76207-4_13}

The authors have retracted this chapter [1] because data sets were mistakenly used without acknowledging the original source or asking for permission. All authors agree to this retraction.

[1] Iyer M., Vutukuru M. (2018) A Planning Tool for TV White Space Deployments. In: Marques P., Radwan A., Mumtaz S., Noguet D., Rodriguez J., Gundlach M. (eds) Cognitive Radio Oriented Wireless Networks. CrownCom 2017. Lecture Notes of the Institute for Computer Sciences, Social Informatics and Telecommunications Engineering, vol 228. Springer, Cham 